\title{
Article
}

\section{High Incidence of Adverse Outcomes in Haemodialysis Patients with Diabetes with or without Diabetic Foot Syndrome: A 5-Year Observational Study in Lleida, Spain}

\author{
Montserrat Dòria ${ }^{1,2}$, Àngels Betriu ${ }^{3}$ (), Montserrat Belart ${ }^{3}$, Verónica Rosado ${ }^{1}$, Marta Hernández ${ }^{1,4}$, Felipe Sarro ${ }^{5}$, \\ Jordi Real ${ }^{6,7}$, Esmeralda Castelblanco ${ }^{6,7}\left(0\right.$, Linda Roxana Pacheco ${ }^{1}$, Elvira Fernández ${ }^{4}$, Josep Franch-Nadal ${ }^{6,7,8}$, \\ Mònica Gratacòs ${ }^{6}$ and Dídac Mauricio ${ }^{2,6,7,9, *(1)}$
}

check for updates

Citation: Dòria, M.; Betriu, À.; Belart M.; Rosado, V.; Hernández, M.; Sarro, F.; Real, J.; Castelblanco, E.; Pacheco, L.R.; Fernández, E.; et al. High Incidence of Adverse Outcomes in Haemodialysis Patients with Diabetes with or without Diabetic Foot Syndrome: A 5-Year Observational Study in Lleida, Spain. J. Clin. Med. 2021, 10, 1368. https://doi.org/ $10.3390 / \mathrm{jcm} 10071368$

Academic Editors:

Giacomo Garibotto and

Lionel Rostaing

Received: 1 February 2021

Accepted: 23 March 2021

Published: 26 March 2021

Publisher's Note: MDPI stays neutra with regard to jurisdictional claims in published maps and institutional affiliations.

Copyright: (c) 2021 by the authors. Licensee MDPI, Basel, Switzerland. This article is an open access article distributed under the terms and conditions of the Creative Commons Attribution (CC BY) license (https:// creativecommons.org/licenses/by/ $4.0 /)$.
1 Department of Endocrinology \& Nutrition, University Hospital Arnau de Vilanova and Santa Maria, 25198 Lleida, Spain; montserratdoria@gmail.com (M.D.); veviroce@hotmail.com (V.R.); mhernandez.lleida.ics@gencat.cat (M.H.); linda_rox@hotmail.com (L.R.P.)

2 Department of Endocrinology and Nutrition, Hospital de la Santa Creu i Sant Pau, Autonomous University of Barcelona, 08041 Barcelona, Spain

3 Sistemes Renals, 2508 Lleida, Spain; abetriu@sistemes-renals.com (À.B.); mbelart@sistemes-renals.com (M.B.)

4 Lleida Institute for Biomedical Research Dr. Pifarré Foundation IRBLleida, University of Lleida, 25198 Lleida, Spain; elvirafgiraldez@gmail.com

5 Department of Nephrology, University Hospital Arnau de Vilanova and Santa Maria, 25198 Lleida, Spain; Jfsarro.lleida.ics@gencat.cat

6 DAP-Cat group, Unitat de Suport a la Recerca Barcelona, Fundació Institut Universitari per a la recerca a l'Atenció Primària de Salut Jordi Gol i Gurina (IDIAPJGol), 08006 Barcelona, Spain; jordireal@gmail.com (J.R.); esmeraldacas@gmail.com (E.C.); josep.franch@gmail.com (J.F.-N.); monica.gratacos@gmail.com (M.G.)

7 Centre for Biomedical Research on Diabetes and Associated Metabolic Diseases (CIBERDEM), Instituto de Salud Carlos III (ISCIII), 08041 Barcelona, Spain

8 Primary Health Care Center Raval Sud, Gerència d'Atenció Primaria, Institut Català de la Salut, 08001 Barcelona, Spain

9 Faculty of Medicine, University of Vic (UVIC/UCC), 08500 Vic, Spain

* Correspondence: didacmauricio@gmail.com; Tel.: +34-935-565-661

\begin{abstract}
Background: We evaluated whether, in subjects receiving haemodialysis (HD), the presence of diabetic foot syndrome (DFS) was associated with increased mortality compared with subjects with diabetes mellitus (DM) without DFS and with non-diabetic subjects. Methods: Retrospective, observational study in 220 subjects followed for six years. We calculated and compared the frequency and 5-year cumulative incidence of all-cause mortality, cardiovascular (CV) mortality, CV events, major adverse CV events (MACE), and new foot ulcer (FU) or amputation. We also examined prognostic factors of all-cause and CV mortality based on baseline characteristics. Results: DM patients had a 1.98 times higher probability of all-cause mortality than those without DM $(p=0.001)$ and 2.42 times higher likelihood of CV mortality and new FU or amputation ( $p=0.002$ and $p=0.008$, respectively). In the DM cohort, only the risk of a new FU or amputation was 2.69 times higher among those with previous DFS $(p=0.021)$. In patients with DM, older age was the only predictor of all-cause and CV mortality ( $p=0.001$ and $p=0.014$, respectively). Conclusions: Although all-cause and CV mortality were increased on HD subjects with DM, the presence of DFS did not modify the excess risk. Additional studies are warranted to further explore the impact of DFS in subjects with DM undergoing HD.
\end{abstract}

Keywords: diabetes mellitus; haemodialysis; diabetic foot syndrome; foot ulcer; amputation; allcause mortality; cardiovascular mortality; survival

\section{Introduction}

Diabetes mellitus (DM) is the primary cause of chronic kidney disease (CKD) and, alone or in combination with hypertension, the cause of $80 \%$ of end-stage renal disease 
(ESRD) cases [1]. On the one hand, the already high risk in the 10-year cumulative allcause mortality for DM increases by $20 \%$ when accompanied by CKD [1]. The reasons for this increased mortality include the presence of significant cardiovascular disease (CVD), problems with vascular access, increased susceptibility to infectious complications, haemodynamic instability during HD due to autonomic neuropathy, and foot ulcer (FU) [2] On the other hand, the mortality of patients requiring chronic dialysis is higher among subjects with DM, with an estimated 5-year survival as low as 30\% after initiation of haemodialysis (HD) [2]. Similarly, predictors of mortality on HD patients are peripheral artery disease (PAD), presence of foot ulcers, and DM [3]. Indeed, it has been estimated that the mean survival rate of patients on HD and with foot lesions is only 1.8 years [4].

Foot ulcers are one of the pathological aspects of diabetic foot syndrome (DFS) and a chronic complication of DM, frequently associated with subsequent foot amputation and death [5]. For instance, subjects with FU are 2- to 3- times more likely to die than patients without FU, and the risk ratio for all-cause mortality is almost 2-fold higher in subjects with DM and FU than in subjects with DM only [6-13]. Of note, the incidence of DFS is much higher in patients with DM than in the general population across all categories of renal disease (i.e., not requiring replacement therapy, treated with $\mathrm{HD}$ or $\mathrm{PD}$, and requiring renal transplantation or simultaneous pancreas and kidney transplantation) [14]. It has been estimated that up to $95 \%$ of dialysis-treated diabetic patients are at high risk of foot problems, and HD itself is an independent risk factor for foot ulceration, non-healing, and amputation [15-17]. About $20 \%$ of DM patients will develop a FU one year after dialysis initiation, and they also have a higher incidence of new amputations and footrelated hospitalizations [18-20]. Risk factors, associated with the likelihood of developing a foot ulcer or lower limb amputation, other than DM, when in maintenance dialysis, are peripheral artery disease (PAD), peripheral neuropathy $(\mathrm{PN})$, and coronary artery disease (CAD) [21-23].

The difference in mortality rates in DM patients requiring dialysis with or without FU has not been studied by large, and results are, in some cases, inconsistent [3,24,25]. In a previous study conducted by our group, we assessed the prevalence of DFS and other associated conditions in DM patients under renal replacement followed for five months [26]. In the present study, we further evaluated whether the presence of DFS was associated with increased mortality compared with subjects with DM but not FDS and with subjects without DM, followed for six years. Moreover, we evaluated differences in CV event risk and the development of new foot ulcerations and amputations, and predictors of all-cause and CV mortality.

\section{Materials and Methods}

\subsection{Design}

This was a retrospective, observational study comparing two cohorts recruited between November 2010 and March 2011 and followed until December 2017. The first cohort consisted of subjects previously described in a cross-sectional study, namely patients with DM and CKD receiving HD as renal replacement therapy between November 2010 and March 2011. Subjects were recruited from the two dialysis centres available in Lleida's health area, a Northeast region of Spain [26]. The other cohort, from the same geographical and clinical setting, consisted of all prevalent subjects without DM, receiving HD replacement therapy (i.e., at least for one month) up to March 2011 (identical time period as the initial cohort).

\subsection{Studied Variables}

The baseline clinical variables for the cohort of DM patients were those described for the initially recruited cohort, excluding subjects under peritoneal dialysis $(n=7)$ [26]. Briefly, information was obtained on age, gender, HD initiation date, hypertension, dyslipidemia, smoking status, retinopathy, and neuropathy. Patients underwent a detailed foot examination, and the following variables were recorded: current and previous FU, previous 
lower-limb amputations, and the presence of PAD [26]. For the new cohort of non-DM patients, the same data and variables (except for neuropathy and retinopathy) were extracted from the dialysis clinics' quarterly reports, and the results of the vascular explorations were recorded in the electronic clinical history of the Detection and Treatment Unit of Atherothrombotic Diseases (UDETMA). This unit, pertaining to the Nephrology Unit of the Hospital Arnau de Vilanova (Lleida), uses the same methodology and instruments as in our previous report [27]. The baseline vascular disease history was obtained as an additional variable for both patients with or without DM and extracted from the electronic medical records after hospital discharge and the dialysis clinic's quarterly reports. It included any of the following: a history of ischemic heart disease, cerebrovascular disease regardless of the origin, heart failure, PAD, revascularisation procedures, major or minor amputation, and surgical ulcer debridement. During the 6-year follow-up period, and based on hospital discharge data, we also recorded admissions for any cause, the last date when the patient was known to be alive and, if applicable, the date of the end of HD treatment, which could be due to lost to follow-up, renal transplant, or death. In the latter case, the cause of death was recorded as $\mathrm{CV}$, non-CV, or unknown.

\subsection{Statistical Analysis}

In the descriptive analyses of the different groups (i.e., non-DM and DM with or without DFS, defined as previous or current foot ulcer or amputation [FU/A]), categorical variables are presented as absolute and relative frequency, and continuous variables expressed as means \pm standard deviation (SD). The t-test was used for continuous variables and the exact Fisher test for categorical variables to assess differences between groups.

The following events were considered as outcomes: all-cause mortality, CV mortality, the incidence of $\mathrm{CV}$ events (coronary heart disease [CHD], cerebrovascular disease [CeVD], $\mathrm{PAD}$, mesenteric ischemia, and ischemic colitis), the incidence of major adverse $\mathrm{CV}$ events (MACE; including non-fatal cerebrovascular event, non-fatal ischaemic coronary event, or CV death), and new ulcer or need for amputation. Each event's frequency was calculated, and the 5-year cumulative incidence and time-to-event analysis were performed. Hazard ratios (HR) for each outcome by groups based on baseline characteristics were estimated. A standard survival analysis using the Kaplan-Meyer method was conducted to generate the curves with the estimated time-to-event. Finally, HR for each outcome, with 95\% confidence intervals $(95 \% \mathrm{CI})$, were estimated with competing-risks regression based on the Fine and Gray's proportional subhazard model to estimate the probability of each event correctly [28]. Additionally, adjustments were made for age, gender, hypertension, dyslipidaemia, smoking, and any previous CVD. All analyses were conducted with the free software environment for statistical computing R version 3.5.3 (2019-03-11) for Windows.

\section{Results}

The characteristics of the two cohorts are shown in Table 1. Overall, 220 patients on HD were followed for a median of 5 years (1828 days). The mean age was 67.5 years and $60 \%$ were male. Of all HD patients, $38.6 \%(n=85)$ had DM, with a median disease duration of 19.7 years, and most cases were type 2 DM (87.1\%). Previous or current DFS was found in $35.3 \%$ of patients from the overall diabetic HD population, and clinical history of FU (previous or current) or amputation in $6.7 \%$ of subjects without DM.

The main differences between the DM and non-DM cohorts were that patients with DM had a higher prevalence of dyslipidemia and PAD $(p<0.001)$, and history of CHD and CVD ( $p=0.011$ and $p=0.006$, respectively). In the subgroup of DM patients, we observed no differences between those with or without DFS as regards mean age, gender, type of DM, disease duration, or diabetes-related microvascular complications (neuropathy, retinopathy, and nephropathy; Supplementary Table S1). Only clinical history of CVD was more frequent among those with DFS $(p=0.021)$. 
Table 1. Baseline demographic and clinical characteristics of the study population.

\begin{tabular}{|c|c|c|c|c|c|c|}
\hline \multirow[b]{2}{*}{ Variable } & \multirow[b]{2}{*}{$\begin{array}{l}\text { All HD } \\
\text { Patients }\end{array}$} & \multirow[b]{2}{*}{$\begin{array}{l}\text { Patients } \\
\text { without DM } \\
(n=135)\end{array}$} & \multicolumn{2}{|c|}{$\begin{array}{l}\text { Patients with DM } \\
\quad(n=85)\end{array}$} & \multirow[t]{2}{*}{$\begin{array}{c}p \text {-Value } \\
\text { No DM vs. } \\
\text { DM }\end{array}$} & \multirow[t]{2}{*}{$\begin{array}{l}p \text {-Value } \\
\text { No DF vs. } \\
\text { DF }\end{array}$} \\
\hline & & & $\begin{array}{l}\text { No Diabetic } \\
\text { Foot* } \\
(n=55)\end{array}$ & $\begin{array}{l}\text { Diabetic Foot } \\
\quad(n=30)\end{array}$ & & \\
\hline Gender, male, $n(\%)$ & $132(60)$ & $80(59.3)$ & $31(56.4)$ & $21(70.0)$ & 0.888 & 0.317 \\
\hline $\begin{array}{l}\text { Age, years, mean (SD), } \\
n(\%)\end{array}$ & $67.5(16.2)$ & $66.7(17.6)$ & $68.5(13.2)$ & $69.1(14.3)$ & 0.332 & 0.856 \\
\hline Diabetes type, $n(\%)$ & & & & & - & 0.508 \\
\hline Type 1 & $11(5.0)$ & - & $6(10.9)$ & $5(16.7)$ & & \\
\hline Type 2 & 74 (33.6) & - & 49 (89.1) & $25(83.3)$ & & \\
\hline $\begin{array}{l}\text { Duration of DM, years, } \\
\text { median ( } 25 \text { th, } 75 \text { th } \\
\text { percentile) }\end{array}$ & $19.7(13.2 ; 29.7]$ & - & $20.1(11.5 ; 29.7)$ & $18.7(16.1 ; 30.7)$ & - & 0.530 \\
\hline Smoking status, $n(\%)$ & & & & & 0.037 & 0.206 \\
\hline Current & $28(17.2)$ & $22(16.3)$ & $3(5.5)$ & $3(10)$ & & \\
\hline Past & $63(28.6)$ & $32(23.7)$ & $17(30.9)$ & $14(46.7)$ & & \\
\hline Never smoked & $129(58.6)$ & $81(60.0)$ & $35(63.5)$ & $13(43.3)$ & & \\
\hline Hypertension, $n(\%)$ & $189(85.9)$ & $117(86.7)$ & $47(85.5)$ & $25(83.3)$ & 0.835 & 0.764 \\
\hline Dyslipidemia, $n(\%)$ & $107(48.6)$ & $46(34.1)$ & $41(74.5)$ & $20(66.7)$ & $<0.001$ & 0.604 \\
\hline \multicolumn{7}{|l|}{ Clinical history, $n(\%)$} \\
\hline $\mathrm{CHD}$ & $51(23.2)$ & $23(17.0)$ & $17(30.9)$ & $11(36.7)$ & 0.011 & 0.765 \\
\hline CVD & $28(12.7)$ & $10(7.4)$ & $7(12.7)$ & $11(36.7)$ & 0.006 & 0.021 \\
\hline Cardiac arrhythmia & $21(9.5)$ & $13(9.6)$ & $3(5.5)$ & $5(16.7)$ & 1.00 & 0.124 \\
\hline Heart failure & $13(5.9)$ & $5(3.7)$ & $5(9.1)$ & $3(10.0)$ & 0.146 & 1.000 \\
\hline $\mathrm{PAD}, n(\%)$ & $110(50.0)$ & $51(37.8)$ & $37(67.3)$ & $22(73.3)$ & $<0.001$ & 0.461 \\
\hline \multicolumn{7}{|l|}{ Foot ulcer, $n(\%)$} \\
\hline Previous & $22(10)$ & $4(3.0)$ & $0(0.0)$ & $18(60.0)$ & $<0.001$ & $<0.001$ \\
\hline Current & $20(9.1)$ & $4(3.0)$ & $0(0.0)$ & $16(53.3)$ & $<0.001$ & $<0.001$ \\
\hline $\begin{array}{l}\text { Previous amputation, } n \\
(\%)\end{array}$ & & & & & $<0.001$ & $<0.001$ \\
\hline No amputation & $202(91.8)$ & $131(97.0)$ & $55(100)$ & $16(53.3)$ & & \\
\hline Major & $7(3.2)$ & $1(0.7)$ & $0(0.0)$ & $6(20.0)$ & & \\
\hline
\end{tabular}

${ }^{*}$ Diabetic foot defined as previous or current foot ulcer or amputation; CHD, coronary heart disease; CVD, cardiovascular disease; PAD, peripheral artery disease.

\subsection{Outcomes at 5-Years}

After five years of follow-up, 52 patients (23.6\%) on HD underwent renal transplant, which was less frequent in DM patients $(11.8 \%$ vs. $31.1 \% ; p<0.001)$. Only one patient was lost to follow-up.

At the end of the follow-up, more than half of the patients had died ( $n=123 ; 55.9 \%)$. The all-cause mortality was significantly more frequent among patients with DM than without $(p<0.001)$, as were CV deaths $(p<0.001)$, CV events $(p=0.001)$, MACE $(p=0.001)$, and the incidence of FU or need of amputation $(p<0.001)$ (Figure 1a). 


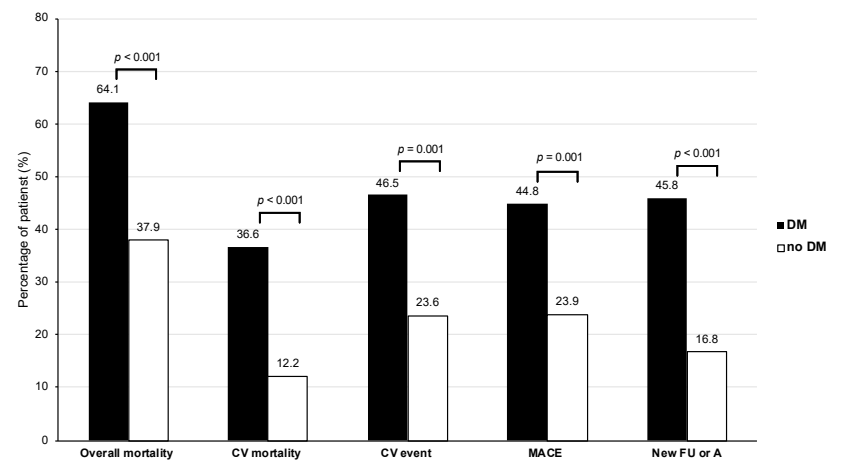

(a)

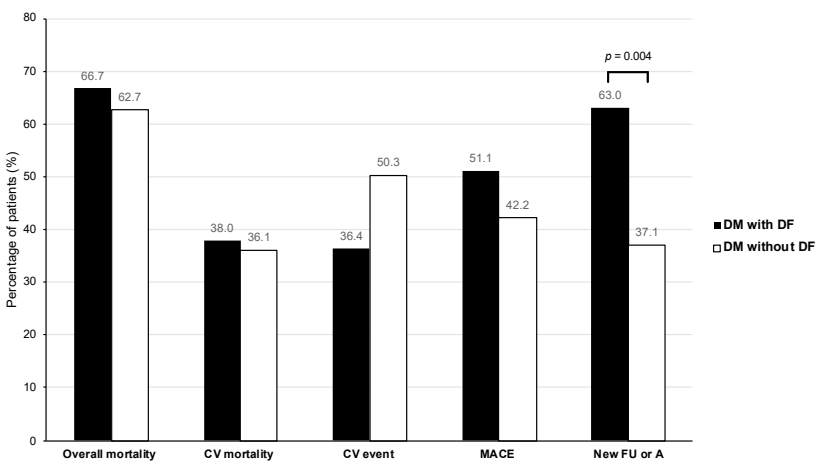

(b)

Figure 1. Percentage of patients on haemodialysis with studied clinical outcomes at 5-years of follow-up based on the presence of diabetes mellitus (a) and on the presence or absence of previous diabetic foot (b). CV, cardiovascular; DF, diabetic foot (ulcer or amputation); DM, diabetes mellitus; MACE, major adverse CV event.

Among those DM patients on HD $(n=85)$, the only clinical outcome that was significantly elevated among those with DFS was the development of a new FU or the need for amputation ( $p=0.004$; Figure 1b).

The Kaplan-Meyer curves showed that, for all-cause mortality, CV mortality, and new FU or amputation, the median time to each outcome was shorter among those with DM (Supplementary Figure S1). As such, patients with DM had an almost 2-fold higher probability of all-cause mortality compared with those without DM $(\mathrm{HR}=1.98)$, and a more than 2-fold higher likelihood of $\mathrm{CV}$ mortality or new ulcer or amputation ( $\mathrm{HR}=2.42$; and $\mathrm{HR}=2.29$, respectively) (Figure 2a). In contrast, the risk of an incident CV event or MACE was comparable between those with or without DM.

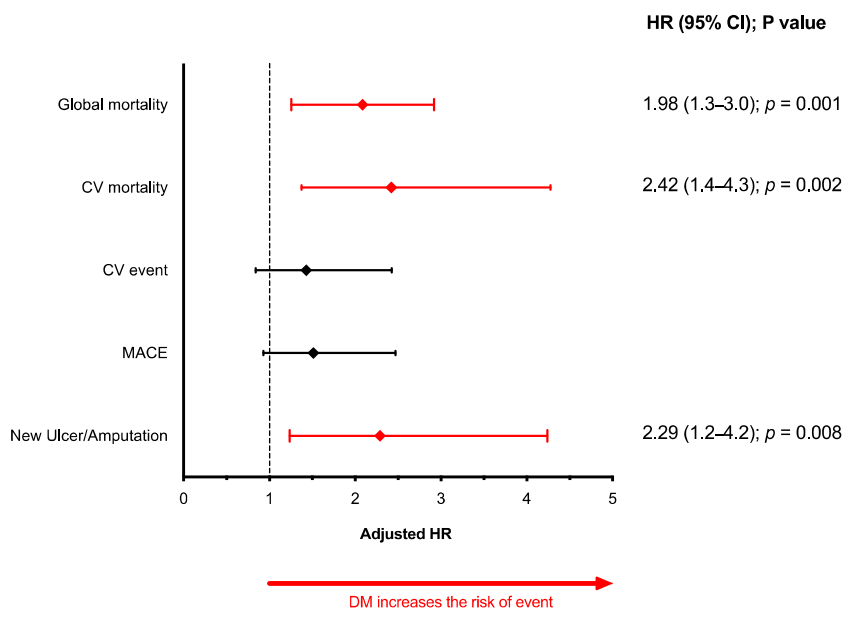

(a)

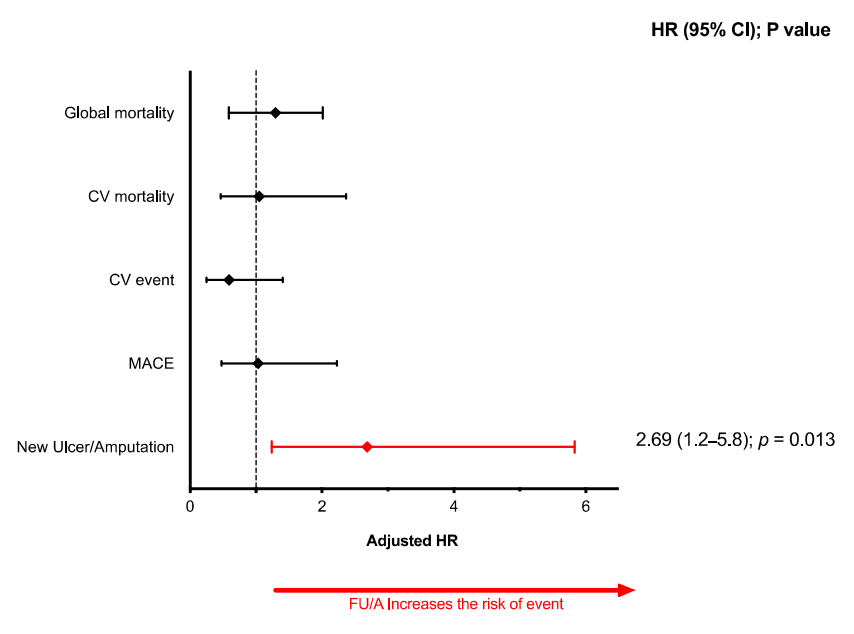

(b)

Figure 2. Adjusted hazard ratios for each of the studied outcomes based on the presence of diabetes mellitus (a) and on the presence or absence of previous diabetic foot (b). CV, cardiovascular; HR, hazard ratio; MACE, major adverse cardiovascular event.

When only considering the DM patient cohort, the median time to all-cause death, CV death, a CV event, or a MACE was similar between those with DFS compared with those without, but it was significantly shorter for the appearance of a new FU or need for amputation among those with previous DFS (Supplementary Figure S2). Specifically, the risk of a new ulcer or amputation was 2.69 times higher among those with previous DFS than those without $(p=0.021)$ (Figure 2b). 


\subsection{Predictors of All-Cause Mortality and CV Mortality}

\subsubsection{Overall Dialysis Population}

The all-cause mortality in the overall HD population was more likely among those with older age, DM, antecedents of cardiac conditions (i.e., CHD, CVD, arrhythmia, and HF), diabetes-related microvascular complications (i.e., diabetic retinopathy and neuropathy), $\mathrm{PAD}$, previous $\mathrm{FU}$, and both previous minor and major amputations (Table 2). When only considering deaths attributable to $\mathrm{CV}$ events, females were at lower risk, but previous FU and minor or major amputations were not associated with a higher likelihood of CV mortality.

Table 2. Predictors of all-cause mortality and cardiovascular mortality in patients on haemodialysis $(n=220)$.

\begin{tabular}{|c|c|c|}
\hline & All-Cause Mortality & CV Mortality \\
\hline Variable & $\begin{array}{c}\text { Hazard Ratio } \\
(95 \% \text { CI }) ; p \text {-Value }\end{array}$ & $\begin{array}{c}\text { Hazard Ratio } \\
(95 \% \text { CI); } p \text {-Value }\end{array}$ \\
\hline Gender (female) & $0.69(0.48-1.00) ; 0.051$ & $0.45(0.24-0.86) ; 0.015$ \\
\hline Age (years) & $1.05(1.03-1.07) ;<0.001$ & $1.04(1.01-1.06) ; 0.001$ \\
\hline $\mathrm{DM}$ & $1.90(1.33-2.71) ;<0.001$ & $3.15(1.76-5.63) ;<0.001$ \\
\hline DM duration (years) & $1.00(0.98-1.03) ; 0.826$ & $1.01(0.98-1.04) ; 0.659$ \\
\hline Hypertension & 1.06 (0.63-1.79); 0.832 & 0.69 (0.33-1.42); 0.314 \\
\hline Dyslipidaemia & $1.06(0.75-1.52) ; 0.728$ & $1.48(0.83-2.62) ; 0.183$ \\
\hline Smoker & $0.76(0.42-1.36) ; 0.353$ & $0.79(0.30-2.06) ; 0.630$ \\
\hline $\mathrm{CHD}$ & $1.54(1.04-2.28) ; 0.031$ & 2.19 (1.21-3.95); 0.010 \\
\hline CVD & $1.70(1.06-2.72) ; 0.027$ & $2.52(1.28-4.95) ; 0.007$ \\
\hline Arrhythmia & 1.92 (1.14-3.26); 0.015 & $2.28(1.02-5.09) ; 0.045$ \\
\hline $\mathrm{HF}$ & 2.39 (1.31-4.37); 0.004 & $2.68(1.05-6.84) ; 0.038$ \\
\hline PAD & $2.09(1.32-3.32) ; 0.002$ & $2.27(1.10-4.68) ; 0.027$ \\
\hline Diabetic retinopathy & $2.32(1.56-3.43) ;<0.001$ & $4.09(2.20-7.59) ;<0.001$ \\
\hline Diabetic neuropathy & $1.92(1.34-2.76) ;<0.001$ & $3.04(1.69-5.46) ;<0.001$ \\
\hline Previous FU & $2.10(1.27-3.47) ; 0.004$ & $2.22(0.99-4.95) ; 0.053$ \\
\hline Current FU & $1.69(0.98-2.90) ; 0.058$ & $2.12(0.95-4.73) ; 0.066$ \\
\hline Previous minor amputation & 2.43 (1.27-4.67); 0.007 & $2.58(0.92-7.23) ; 0.071$ \\
\hline Previous major amputation & $3.33(1.54-7.21) ; 0.002$ & 1.32 (0.18-9.65); 0.785 \\
\hline
\end{tabular}

CHD, coronary heart disease; CVD, cardiovascular disease; D, diabetic; FU, foot ulcer; HF, heart failure; DM, diabetes mellitus; PAD, peripheral artery disease; T1DM, type 1 diabetes mellitus; T2DM, type 2 diabetes mellitus.

\subsubsection{DM Cohort}

Among DM patients, older age was the only risk factor associated with increased probability of all-cause and CV mortality (Table 3). Moreover, diabetic retinopathy was a predictor of increased risk for overall mortality. Thus, neither the presence of previous or current FU, nor history of minor or major amputations were predictors of an increased global or CV mortality. 
Table 3. Predictors of all-cause mortality and cardiovascular mortality in patients with diabetes mellitus $(n=85)$.

\begin{tabular}{|c|c|c|}
\hline & All-Cause Mortality & CV Mortality \\
\hline Variable & $\begin{array}{c}\text { Hazard Ratio } \\
(95 \% \text { CI }) ; p \text {-Value }\end{array}$ & $\begin{array}{c}\text { Hazard Ratio } \\
(95 \% \text { CI }) ; p \text {-Value }\end{array}$ \\
\hline Gender (female) & $0.72(0.42 ; 1.22) ; 0.224$ & $0.51(0.22 ; 1.14) ; 0.102$ \\
\hline Age (years) & $1.04(1.02 ; 1.06) ; 0.001$ & $1.04(1.01 ; 1.08) ; 0.014$ \\
\hline DM duration (years) & $1.00(0.98 ; 1.03) ; 0.826$ & $1.01(0.98 ; 1.04) ; 0.659$ \\
\hline Hypertension & $0.90(0.44 ; 1.83) ; 0.776$ & $0.63(0.26 ; 1.55) ; 0.313$ \\
\hline Dyslipidaemia & $0.81(0.46 ; 1.41) ; 0.451$ & $1.63(0.62 ; 4.28) ; 0.320$ \\
\hline Smoker & $1.13(0.40 ; 3.20) ; 0.813$ & $0.57(0.08 ; 4.28) ; 0.585$ \\
\hline CHD & $1.29(0.76 ; 2.19) ; 0.339$ & $1.59(0.76 ; 3.34) ; 0.217$ \\
\hline CVD & $1.58(0.89 ; 2.80) ; 0.119$ & $1.71(0.76 ; 3.88) ; 0.197$ \\
\hline Arrhythmia & $1.56(0.71 ; 3.43) ; 0.272$ & $2.32(0.88 ; 6.08) ; 0.088$ \\
\hline $\mathrm{HF}$ & $1.41(0.64 ; 3.12) ; 0.399$ & $2.06(0.78 ; 5.46) ; 0.144$ \\
\hline PAD & $1.70(0.90 ; 3.20) ; 0.101$ & $1.44(0.55 ; 3.79) ; 0.456$ \\
\hline Diabetic retinopathy & $6.51(1.57 ; 27.0) ; 0.010$ & *; 0.998 \\
\hline Diabetic neuropathy & *; 0.997 & *; 0.998 \\
\hline Previous FU & $1.52(0.85 ; 2.73) ; 0.159$ & $1.23(0.50 ; 3.01) ; 0.658$ \\
\hline Current FU & $1.19(0.64 ; 2.20) ; 0.575$ & $1.37(0.58 ; 3.20) ; 0.470$ \\
\hline Previous minor amputation & $1.86(0.84 ; 4.12) ; 0.128$ & $1.55(0.47 ; 5.14) ; 0.477$ \\
\hline Previous major amputation & $2.03(0.86 ; 4.78) ; 0.105$ & $0.68(0.09 ; 5.05) ; 0.706$ \\
\hline
\end{tabular}

CHD, coronary heart disease; CVD, cardiovascular disease; $\mathrm{D}$, diabetic; FU, foot ulcer; HF, heart failure; DM, diabetes mellitus; PAD, peripheral artery disease; T1DM, type 1 diabetes mellitus; T2DM, type 2 diabetes mellitus.

* Not calculated because all the patients with the event also had diabetic neuropathy or retinopathy.

\section{Discussion}

The current observational study showed that, in patients with DM undergoing HD replacement therapy, the risk of all-cause and CV mortality and incident FU or amputation was increased compared with those without DM. However, the 5-year survival probability was similar for diabetic patients with or without DFS, thus not modifying the already elevated risk for overall and CV mortality.

More than half of the patients died during our study, which is in line with previous reports showing that the 5-year survival probability in patients in maintenance HD is around $42-45 \%$ [29-31]. Moreover, and also in agreement with previous studies [2], the mortality rates were significantly higher among patients with DM ( $64 \%$ vs. $38 \%)$, with a 2 -fold reduced probability of 5-year survival compared with non-diabetic subjects.

The survival of HD patients with foot lesions is very poor and estimated at $23 \%$ at five years [4]. This figure was similar in our cohort (33.3\%). However, it was unexpected that the rates of all-cause and CV mortality, MACE, or CV events were similar between patients with and without DFS. Firstly, several studies have consistently shown that the rate of death, myocardial infarction, and fatal stroke in patients with DM is higher among those with FU [12,32-35]. Of note, although the main cause of mortality is CVD, a metaanalysis reported that the proportion of deaths attributable to $\mathrm{CV}$ causes was similar among patients with or without FU [12]. Moreover, a large study conducted in the US reported that the severity of diabetic FU at presentation predicted subsequent mortality to a greater extent than prior CVD [33]. Secondly, few studies have addressed these outcomes on HD patients with DM and concomitant FU $[3,24]$. Our results are not in agreement with a study conducted by Al-Thani et al., in Qatar, including $252 \mathrm{HD}$ patients, where the 5-year mortality was higher among patients with diabetes and FU vs. those without FU ( $83 \%$ vs. 
$58 \%$ ) [3]. Our results are also in disagreement with another study conducted by Garimella et al., in the US in 14,103 people with diabetes on dialysis, where death was more likely among patients with incident FU ( $n=1769 ; 25.5 \%$ deaths) than among those at-risk (no FU during follow-up; $n=11,750 ; 19.1 \%$ deaths) [24]. The explanation for these apparent discrepancies may be related to methodological and population differences between the studies. The Al-Thani et al., study included an HD population considerably younger than ours (almost 13 years younger for those without $\mathrm{FU}$, and seven years younger for those with FU), and less likely to have DM plus FU than ours (23\% vs. $35.5 \%)$. Moreover, while their FU cohort had increased age, nephropathy, retinopathy, coronary artery disease, and PAD compared with the non-FU cohort, we only observed a slightly increased CVD prevalence among those with DM and FU vs. those without FU (36.7\% vs. $30.9 \%)$. Regarding the Garimella et al. study, the authors included subjects with incident FU and excluded those with a prevalent ulcer at first foot-check. In contrast, we studied patients with both previous and prevalent FU (60\% and $53.3 \%$, respectively). Therefore, the populations studied are not comparable and possibly had different comorbidities, such as diabetesrelated complications (e.g., micro- and macrovascular diseases). Indeed, it was previously reported that the impact of variables associated with $\mathrm{CV}$ risk is greater among subjects presenting their first diabetic FU and that the variables related to the risk of dying are different between those with or without a history of previous FU [36].

The risk factors influencing all-cause and CV mortality in patients undergoing $\mathrm{HD}$ are multiple and include DM, age, previous CVD, and haemodialysis duration [37]. Moreover, the characteristics of patients with DM in dialysis differ from those without DM: diabetic patients are older, present more CVD, and are less likely to be transplanted [38]. These differences were also observed in our study, where T2DM, older age, antecedents of cardiac conditions (i.e., CHD, CVD, arrhythmia, and HF), diabetes-related microvascular complications (i.e., diabetic retinopathy and neuropathy), PAD, previous FU, and both previous minor and major amputations were identified as risk factors for all-cause mortality among HD subjects. However, age and retinopathy were the only risk factors for all-cause mortality among the subcohort of DM patients, and only age was predictive of CV mortality. In line with our results, a study on the characteristics of patients with DM that survived up to 11 years on HD showed that the risk of mortality increased by $3 \%$ per year increase in age [39]. Moreover, diabetic retinopathy was previously identified as an independent predictor of 3-year all-cause mortality among HD patients [40].

In our HD population, the occurrence of a new FU or amputation was more likely among patients with DM vs. non-DM, and among those with DFS vs. DM only. A history of prior FU or lower-limb amputation are conditions known to increase the risk of diabetic FU development [41,42], which was also observed in our study. However, neither the probability of all-cause nor CV mortality were predicted by previous DFS. This concords with a study conducted in Italy including a small cohort of diabetic HD subjects with critical limb ischemia and FU treated by endovascular revascularization $(n=99)$, where no variable predicted death after 12-months of follow-up [25]. Actually, HD itself is a risk factor for incident FU and amputations [16,17,43], and impaired renal function is, in turn, an independent predictor of healing failure, first amputation, and mortality [44].

The main strength of this study is that it is the first to assess mortality among DM patients with DFS on HD in our region, which included patients encompassing the entire haemodialysis population of Lleida (Spain). However, our results might not necessarily reflect those of other regions or countries with different healthcare systems or resources. For instance, mortality rates in diabetic patients with FU or amputations have been shown to vary between regions in the US, with decreased survival in those with fewer annual office visits and higher hospital admission rates [45]. Another strength is that we collected data on a wide range of comorbid conditions and chronic diabetes-related complications, such as diabetic retinopathy, reflecting the severity of microangiopathic complications of the disease. Still, the results of our study must be viewed in the context of some limitations. The main one is the retrospective nature of the design, where only association, but not 
causation, may be inferred from the observations. Besides, since the study was subject to pre-existing records, it is possible that not all were complete or not all potential risk factors were identified and subsequently recorded. Most importantly, we had no data on the treatment modality (i.e., conventional HD with low-flux or high-flux membranes, or hemodiafiltration), adequacy parameters (e.g., urea dialysis dose through the $\mathrm{Kt} / \mathrm{V}$ value), presence of anaemia, or mineral metabolism parameters (e.g., calcium-phosphorus product or parathyroid hormone level). These variables are known to have a significant influence in HD patient's survival and are thus potential confounding factors that were not taken into account in the study. This may have biased any association observed. Moreover, many different professionals were involved in patient care and the length of follow-up was substantial. This could have led to different measurements of the studied outcomes and risk factors throughout the database, making them less accurate and consistent than that achieved with a prospective cohort study design. Finally, we cannot discard the presence of unknown potential confounders. Another limitation was the small sample size of patients with DM and the even more reduced size of the subgroups with or without DFS. The sample size was inherently limited by the availability of subjects in the health area studied and the epidemiology of the disease. The small sample size raises the possibility that, even if there is a difference in outcomes between patients with and without DFS, we did not have enough statistical power to detect a relevant difference, and we cannot discard the absence of an actual effect (type II error). For instance, the overall mortality was very high among the DM cohort (64.1\%), but similar between those with or without DFS (66.7\% vs. $62.7 \%$ ). Moreover, the small sample size could have also led to significant results in the absence of an actual effect (type I error). Given these limitations, the present results should be viewed as one piece of evidence, and it is necessary to perform additional studies with a larger number of subjects to detect small effects and thereby yield more significant results.

\section{Conclusions}

The major finding of our study is that DFS seems to be a condition that does not modify the pre-existing high risk of mortality among diabetic patients compared with non-diabetic subjects. These preliminary results would argue that the excess mortality attributed to DFS actually reflects the sum of chronic micro- and macrovascular diabetesrelated complications, renal impairment, and HD itself. As such, there is a need for new and intensive interventions to improve the management of patients on HD with diabetes, and subsequently reduce the high mortality rates associated with the disease.

Supplementary Materials: The following are available online at https:/ / www.mdpi.com/article/ 10.3390/jcm10071368/s1, Table S1: diabetes-related microvascular complications recorded in the populations studied, Figure S1: Kaplan-Meyer survival curves in patients with DM vs. those without, regarding the clinical outcomes studied, Figure S2: Kaplan-Meyer survival curves in patients with DM comparing those with and without prior diabetic foot.

Author Contributions: Conceptualization, À.B., M.H., E.F., and D.M.; methodology, M.D., À.B., M.H., E.F. and D.M.; investigation, M.D., À.B., M.B., V.R., F.S., L.R.P., M.H., J.F.-N., and D.M.; validation, D.M. and E.C.; formal analysis, J.R. and E.C.; resources, À.B., M.B., M.H., F.S., J.F.-N. and D.M.; data curation, M.D., À.B., M.B. and E.C.; writing-original draft preparation, M.D. and M.G.; writing-review and editing, M.G. and D.M.; supervision D.M. All authors have read and agreed to the published version of the manuscript.

Funding: This research received no external funding.

Institutional Review Board Statement: The study was conducted according to the guidelines of the Declaration of Helsinki and approved by the Ethics Committee from the Hospital Arnau de Vilanova (Lleida, Spain).

Informed Consent Statement: Informed consent was obtained from all subjects involved in the study.

Data Availability Statement: The data presented in this study available on request from the corresponding author. 
Acknowledgments: The authors thank the patients who participated in the study. CIBER of Diabetes and Associated Metabolic Diseases (CIBERDEM) is an initiative from Instituto de Salud Carlos III. This work has developed within the framework of the Doctorate in the Department of Medicine, Autonomous University of Barcelona. The authors acknowledge Helena Kruyer for language editing and proofreading.

Conflicts of Interest: The authors declare no conflict of interest.

\section{References}

1. Koye, D.N.; Magliano, D.J.; Nelson, R.G.; Pavkov, M.E. The Global Epidemiology of Diabetes and Kidney Disease. Adv. Chronic Kidney Dis. 2018, 25, 121-132. [CrossRef]

2. Ghaderian, S.B.; Hayati, F.; Shayanpour, S.; Beladi Mousavi, S.S. Diabetes and end-stage renal disease; a review article on new concepts. J Ren. Inj. Prev. 2015, 4, 28-33. [PubMed]

3. Al-Thani, H.; El-Menyar, A.; Koshy, V.; Hussein, A.; Sharaf, A.; Asim, M.; Sadek, A. Implications of foot ulceration in hemodialysis patients: A 5-year observational study. J. Diabetes Res. 2014, 2014, 945075. [CrossRef]

4. Orimoto, Y.; Ohta, T.; Ishibashi, H.; Sugimoto, I.; Iwata, H.; Yamada, T.; Tadakoshi, M.; Hida, N. The prognosis of patients on hemodialysis with foot lesions. J. Vasc. Surg. 2013, 58, 1291-1299. [CrossRef]

5. Dietrich, I.; Braga, G.A.; de Melo, F.G.; da Costa Silva Silva, A.C.C. The Diabetic Foot as a Proxy for Cardiovascular Events and Mortality Review. Curr. Atheroscler. Rep. 2017, 19, 44. [CrossRef] [PubMed]

6. Walsh, J.W.; Hoffstad, O.J.; Sullivan, M.O.; Margolis, D.J. Association of diabetic foot ulcer and death in a population-based cohort from the United Kingdom. Diabet. Med. 2016, 33, 1493-1498. [CrossRef]

7. Iversen, M.M.; Tell, G.S.; Riise, T.; Hanestad, B.R.; Ostbye, T.; Graue, M.; Midthjell, K. History of foot ulcer increases mortality among individuals with diabetes: Ten-year follow-up of the Nord-Trondelag Health Study, Norway. Diabetes Care 2009, 32, 2193-2199. [CrossRef] [PubMed]

8. Ramsey, S.D.; Newton, K.; Blough, D.; McCulloch, D.K.; Sandhu, N.; Reiber, G.E.; Wagner, E.H. Incidence, outcomes, and cost of foot ulcers in patients with diabetes. Diabetes Care 1999, 22, 382-387. [CrossRef] [PubMed]

9. Boyko, E.J.; Ahroni, J.H.; Smith, D.G.; Davignon, D. Increased mortality associated with diabetic foot ulcer. Diabetes Med. 1996, 13, 967-972. [CrossRef]

10. Moulik, P.K.; Mtonga, R.; Gill, G.V. Amputation and mortality in new-onset diabetic foot ulcers stratified by etiology. Diabetes Care 2003, 26, 491-494. [CrossRef]

11. Hoffstad, O.; Mitra, N.; Walsh, J.; Margolis, D.J. Diabetes, lower-extremity amputation, and death. Diabetes Care 2015, 38, 1852-1857. [CrossRef]

12. Brownrigg, J.R.; Davey, J.; Holt, P.J.; Davis, W.A.; Thompson, M.M.; Ray, K.K.; Hinchliffe, R.J. The association of ulceration of the foot with cardiovascular and all-cause mortality in patients with diabetes: A meta-analysis. Diabetologia 2012, 55, $2906-2912$. [CrossRef] [PubMed]

13. Jeyaraman, K.; Berhane, T.; Hamilton, M.; Chandra, A.P.; Falhammar, H. Mortality in patients with diabetic foot ulcer: A retrospective study of 513 cases from a single Centre in the Northern Territory of Australia. BMC Endocr. Disord. 2019, 19, 1-7. [CrossRef]

14. Valabhji, J. Foot problems in patients with diabetes and chronic kidney disease. J Ren. Care 2012, 38 (Suppl. S1), 99-108. [CrossRef] [PubMed]

15. Ndip, A.; Lavery, L.A.; Lafontaine, J.; Rutter, M.K.; Vardhan, A.; Vileikyte, L.; Boulton, A.J. High levels of foot ulceration and amputation risk in a multiracial cohort of diabetic patients on dialysis therapy. Diabetes Care 2010, 33, 878-880. [CrossRef] [PubMed]

16. Ndip, A.; Rutter, M.K.; Vileikyte, L.; Vardhan, A.; Asari, A.; Jameel, M.; Tahir, H.A.; Lavery, L.A.; Boulton, A.J. Dialysis treatment is an independent risk factor for foot ulceration in patients with diabetes and stage 4 or 5 chronic kidney disease. Diabetes Care 2010, 33, 1811-1816. [CrossRef] [PubMed]

17. Jaar, B.G.; Astor, B.C.; Berns, J.S.; Powe, N.R. Predictors of amputation and survival following lower extremity revascularization in hemodialysis patients. Kidney Int. 2004, 65, 613-620. [CrossRef] [PubMed]

18. Gilhotra, R.A.; Rodrigues, B.T.; Vangaveti, V.N.; Malabu, U.H. Prevalence and Risk Factors of Lower Limb Amputation in Patients with End-Stage Renal Failure on Dialysis: A Systematic Review. Int. J. Nephrol. 2016, 2016, 4870749. [CrossRef]

19. Combe, C.; Albert, J.M.; Bragg-Gresham, J.L.; Andreucci, V.E.; Disney, A.; Fukuhara, S.; Goodkin, D.A.; Gillespie, B.W.; Saito, A.; Jadoul, M.; et al. The burden of amputation among hemodialysis patients in the Dialysis Outcomes and Practice Patterns Study (DOPPS). Am. J. Kidney Dis. 2009, 54, 680-692. [CrossRef]

20. Lavery, L.A.; Lavery, D.C.; Hunt, N.A.; La Fontaine, J.; Ndip, A.; Boulton, A.J. Amputations and foot-related hospitalisations disproportionately affect dialysis patients. Int. Wound J. 2015, 12, 523-526. [CrossRef]

21. Kaminski, M.; Frescos, N.; Tucker, S. Prevalence of risk factors for foot ulceration in patients with end-stage renal disease on haemodialysis. Intern. Med. J. 2012, 42, e120-e128. [CrossRef] [PubMed]

22. Kaminski, M.R.; Raspovic, A.; McMahon, L.P.; Strippoli, G.F.; Palmer, S.C.; Ruospo, M.; Dallimore, S.; Landorf, K.B. Risk factors for foot ulceration and lower extremity amputation in adults with end-stage renal disease on dialysis: A systematic review and meta-analysis. Nephrol. Dial. Transpl. 2015, 30, 1747-1766. [CrossRef] 
23. Jones, N.J.; Chess, J.; Cawley, S.; Phillips, A.O.; Riley, S.G. Prevalence of risk factors for foot ulceration in a general haemodialysis population. Int. Wound J. 2013, 10, 683-688. [CrossRef]

24. Garimella, P.S.; Wang, W.; Lin, S.F.; Hymes, J.; Lacson, E., Jr. Incident diabetic foot ulcers and mortality in hemodialysis patients. Hemodial. Int. 2017, 21, 145-147. [CrossRef]

25. Meloni, M.; Giurato, L.; Izzo, V.; Stefanini, M.; Pampana, E.; Gandini, R.; Uccioli, L. Long term outcomes of diabetic haemodialysis patients with critical limb ischemia and foot ulcer. Diabetes Res. Clin. Pr. 2016, 116, 117-122. [CrossRef] [PubMed]

26. Doria, M.; Rosado, V.; Pacheco, L.R.; Hernandez, M.; Betriu, A.; Valls, J.; Franch-Nadal, J.; Fernandez, E.; Mauricio, D. Prevalence of Diabetic Foot Disease in Patients with Diabetes Mellitus under Renal Replacement Therapy in Lleida, Spain. BioMed Res. Int. 2016, 2016, 7217586. [CrossRef] [PubMed]

27. Junyent, M.; Gilabert, R.; Nunez, I.; Corbella, E.; Vela, M.; Zambon, D.; Ros, E. Carotid ultrasound in the assessment of preclinical atherosclerosis. Distribution of intima-media thickness values and plaque frequency in a Spanish community cohort. Med. Clin. 2005, 125, 770-774. [CrossRef]

28. Fine, J.P.; Gray, R.J. A proportional hazards model for the subdistribution of a competing risk. J. Am. Stat. Assoc. 1999, 94, 496-509. [CrossRef]

29. Beladi Mousavi, S.S.; Hayati, F.; Alemzadeh Ansari, M.J.; Valavi, E.; Cheraghian, B.; Shahbazian, H.; Golzari, K.; Ghorbani, A.; Rashidi, H.; Payami, P.; et al. Survival at 1,3, and 5 years in diabetic and nondiabetic patients on hemodialysis. Iran. J. Kidney Dis. 2010, 4, 74-77.

30. Beladi-Mousavi, S.S.; Alemzadeh-Ansari, M.J.; Alemzadeh-Ansari, M.H.; Beladi-Mousavi, M. Long-term survival of patients with end-stage renal disease on maintenance hemodialysis: A multicenter study in Iran. Iran. J. Kidney Dis. 2012, 6, 452-456.

31. United States Renal Data System (USRDS). 2019 Annual Data Report: Epidemiology of Kidney Disease in the United States. Available online: https://www.usrds.org/media/2371/2019-executive-summary.pdf (accessed on 1 October 2020).

32. Jupiter, D.C.; Thorud, J.C.; Buckley, C.J.; Shibuya, N. The impact of foot ulceration and amputation on mortality in diabetic patients. I: From ulceration to death, a systematic review. Int. Wound J. 2016, 13, 892-903. [CrossRef]

33. Brennan, M.B.; Hess, T.M.; Bartle, B.; Cooper, J.M.; Kang, J.; Huang, E.S.; Smith, M.; Sohn, M.W.; Crnich, C. Diabetic foot ulcer severity predicts mortality among veterans with type 2 diabetes. J. Diabetes Complicat. 2017, 31, 556-561. [CrossRef]

34. Morbach, S.; Furchert, H.; Groblinghoff, U.; Hoffmeier, H.; Kersten, K.; Klauke, G.T.; Klemp, U.; Roden, T.; Icks, A.; Haastert, B.; et al. Long-term prognosis of diabetic foot patients and their limbs: Amputation and death over the course of a decade. Diabetes Care 2012, 35, 2021-2027. [CrossRef]

35. Rubio, J.A.; Jimenez, S.; Alvarez, J. Clinical characteristics and mortality in patients treated in a Multidisciplinary Diabetic Foot Unit. Endocrinol. Diabetes Nutr. 2017, 64, 241-249. [CrossRef]

36. Rigor, J.; Martins-Mendes, D.; Monteiro-Soares, M. Risk factors for mortality in patients with a diabetic foot ulcer: A cohort study. Eur. J. Intern. Med. 2020, 71, 107-110. [CrossRef]

37. Ma, L.; Zhao, S. Risk factors for mortality in patients undergoing hemodialysis: A systematic review and meta-analysis. Int. J. Cardiol. 2017, 238, 151-158. [CrossRef]

38. Karame, A.; Labeeuw, M.; Trolliet, P.; Caillette-Beaudoin, A.; Cahen, R.; Ecochard, R.; Galland, R.; Hallonet, P.; Pouteil-Noble, C.; Villar, E. The Impact of type 2 diabetes on mortality in end-stage renal disease patients differs between genders. Nephron Clin. Pr. 2009, 112, c268-c275.

39. Triebswetter, S.; Gutjahr-Lengsfeld, L.J.; Schmidt, K.R.; Drechsler, C.; Wanner, C.; Krane, V. Long-Term Survivor Characteristics in Hemodialysis Patients with Type 2 Diabetes. Am. J. Nephrol. 2018, 47, 30-39. [CrossRef] [PubMed]

40. El-Menyar, A.; Al Thani, H.; Hussein, A.; Sadek, A.; Sharaf, A.; Al Suwaidi, J. Diabetic retinopathy: A new predictor in patients on regular hemodialysis. Curr. Med. Res. Opin. 2012, 28, 999-1055. [CrossRef] [PubMed]

41. Crawford, F.; Inkster, M.; Kleijnen, J.; Fahey, T. Predicting foot ulcers in patients with diabetes: A systematic review and meta-analysis. QJM 2007, 100, 65-86. [CrossRef] [PubMed]

42. Monteiro-Soares, M.; Boyko, E.J.; Ribeiro, J.; Ribeiro, I.; Dinis-Ribeiro, M. Risk stratification systems for diabetic foot ulcers: A systematic review. Diabetologia 2011, 54, 1190-1199. [CrossRef]

43. Prompers, L.; Schaper, N.; Apelqvist, J.; Edmonds, M.; Jude, E.; Mauricio, D.; Uccioli, L.; Urbancic, V.; Bakker, K.; Holstein, P.; et al. Prediction of outcome in individuals with diabetic foot ulcers: Focus on the differences between individuals with and without peripheral arterial disease. The EURODIALE Study. Diabetologia 2008, 51, 747-755. [CrossRef] [PubMed]

44. Ghanassia, E.; Villon, L.; Thuan Dit Dieudonne, J.F.; Boegner, C.; Avignon, A.; Sultan, A. Long-term outcome and disability of diabetic patients hospitalized for diabetic foot ulcers: A 6.5-year follow-up study. Diabetes Care 2008, 31, 1288-1292. [CrossRef] [PubMed]

45. Sargen, M.R.; Hoffstad, O.; Margolis, D.J. Geographic variation in Medicare spending and mortality for diabetic patients with foot ulcers and amputations. J. Diabetes Complicat. 2013, 27, 128-133. [CrossRef] [PubMed] 